\title{
REDOMAS DE VIDRO: RELAÇÕES ENTRE TATO, CULTURA MATERIAL E PRÁTICAS DE INSTITUCIONALIZAÇÃO
}

\author{
Glass Cases: The Relationships Between Touch, Material Culture and \\ Institutionalization's Practices \\ Cajas de Vidrio: Relaciones Entre Tato, Cultura Material y lãs Prácticas de \\ Institucionalizacion
}

Dr. José Roberto Pellini ${ }^{1}$

\section{RESUMO}

Uma pergunta costuma me atormentar, dada sua aparente obviedade: porque não podemos tocar os objetos em museus? Podemos ver, podemos olhar, mas não podemos interagir com a cultura material institucionalizada. Por quê? Embora a resposta mais óbvia seja a de que o toque pode resultar na destruição dos objetos, acredito que haja algo mais profundo envolto nessa questão, que é a construção do tato como o sentido do inculto, do selvagem. Nesse sentido, tocar ou não tocar estabelece um jogo de autoridade que define o Eu e o Outro. Ao mesmo tempo, ao se excluir a possibilidade da interação corporal com os objetos, limita-se o entendimento do público e perpetua-se um modelo específico de entender o mundo.

Palavras-chave: Toque, Cultura Material, Arqueologia Sensorial.

\begin{abstract}
A question often torments me due to its apparent obviousness: why cannot we touch objects in museums? We can see, we can look at, but we cannot interact with institutionalized material culture. Why? Whilethe most obvious answer is that touching can result in destruction of objects, I believe there is something deeper involved in this matter, which is the construction of the sense of touch as the sense of uneducated, wild men. To touch or not to touch establishes politics of authority that defines the Self and the Other. At the same time, when the possibility of bodily interaction with the objects is excluded, public understanding is limited and a specific model of understanding the world is perpetuated.
\end{abstract}

Keywords: Touch, Material Culture, Sensorial Archaeology.

\section{RESUMEN}

Unapreguntaque me atormenta, dada suaparenteobviedad: porqué no podemostocar los objetos en los museos? Podemosmirar, pero no podemosinteractuar con la cultura material institucionalizada.¿Porqué? Aunque la respuestamásobviaesque el contactopuederesultar en la destrucción de objetos, creoque hay

${ }^{1}$ Laboratório de Arqueologia Sensorial. Departamento de Arqueologia da Universidade Federal de Sergipe. E-mail: jrpellini@gmail.com 
algomásprofundoenvuelto en esteasunto, quees la construcción del sentido del tactocomoinculto, salvaje. Tocar o no tocarestableceunjuego de poderquesirveparaidentificar el yo y el otro.

\section{Palabras clave: Tacto, Cultura Material, ArqueologíaSensorial}

\section{Uma morte lenta e agonizante}

Um dia desses, minha esposa Carol me chamou para ir com ela a um museu. Antes mesmo que ela terminasse o convite, instintivamente disse não. A rapidez e a convicção com que eu respondi a surpreenderam, e, confesso, a mim também. Como não havia espaço para dúvida, acabamos indo à praia em vez de irmos ao museu. O dia estava lindo, com céu azul, calorzinho suportável e o mar claro à nossa frente. Mesmo assim, me sentia incomodado. Entre um mergulho e outro, fiquei remoendo o porquê de eu ter respondido tão rapidamente com um não ao convite para o museu. Acabei chegando à conclusão de que sou como criança: para entender as coisas, preciso tocar, sentir e cheirar, e a ideia de passar uma tarde ensolarada dentro de um museu, andando de lá para cá, olhando para objetos enjaulados em redomas de vidro, sem poder tocar e interagir com nada,soava como uma morte lenta e agonizante.

Boa parte desse sentimento se deve a minha última visita a um museu. Foi em 2013,em Istambul, quando Carole eufomos ao Palácio Topkapi, antiga residência do sultanato otomano, visitar uma exposição de armas islâmicas medievais. O palácio é muito bonito, a infraestrutura exuberante, mas o passeio foi entediante. Andamos durante horas por entre as antigas salas do palácio, olhando cada uma das vitrines como observadores passivos. Chegou um momento em que não aguentávamos mais, tudo parecia igual, distanciado, uma sucessão infinita de objetos estáticos. Era difícil estabelecer alguma conexão entre os objetos e as pessoas que os utilizaram no passado. O próprio arranjo das luzes criava uma atmosfera de sacralidade em torno das peças que só fazia aumentar o distanciamento psicológico frente aos objetos. Talvez se pudéssemos sentir o peso do escudo, ver de perto o brilho da lâmina da espada, a textura da cota de malha, poderíamos mais facilmente nos envolver e assim criar uma relação mais intimista coma Cultura Material. Mesmo hoje, tentando lembrar detalhes da exposição, sinto certa dificuldade. Memórias são evocadas materialmente por meio de horizontes sensuais encarnados, como cheiro, sabor, textura e cor, ou seja, memórias são construídas a partir de nosso engajamento corpóreo com a Cultura Material, e nosso 
envolvimento com a exposição foi inexistente (JONES, 2001). Gell (1998) nos lembra de que a eficácia dos objetos não está apenas em seu aspecto visual, o qualcria um efeito imediato, mas temporário. A maneira pela qualos objetos são mantidos na memória depende diretamente de como se dá o processo de interação com a Cultura Material, e tanto eu quanto Carol, assim como os demais espectadores não interagimos, não experimentamos, não vivenciamos a exposição. Lembro-me do palácio, dos jardins, dos grandes salões e até de alguns detalhes das arquitraves, mas não me lembro dos objetos expostos. Objetos foram feitos para serem experimentados, assim como casas foram feitas para serem habitadas, vestimentas foram criadas para serem vestidas, facas foram feitas para cortar, parafusar e mesmo travar a porta que insiste em bater com o vento. Mas, em museus, não podemos tocar ou experimentar os objetos. Podemos ver, podemos olhar, podemos contemplar, mas não podemos interagir com a Cultura Material institucionalizada.

Entretanto, nem sempre foi assim. Entre os séculos XVI e XVII, as primeiras coleções privadas e mesmo públicas permitiam o acesso aos objetos (PYE, 2007; CHATTERJEE, 2008). Às pessoas era permitidotocar, ouvir, sentir e mesmo experimentar com o paladar os objetos (CLASSEN \& HOWES, 2006). Classen (2007) nos fala do exemplo de Samuel Pepys que, em seus diários, relata ter beijado o cadáver exposto da rainha Katherine, mulher de Henrique V, em 1669, quando visitava a Abadia de Westminster. O próprio Pepys relata em seus diários que, ao visitar um pintor holandêsde nome Everelst, que havia chegado recentemente a Londres, sentiu-se "forçado de novo e de novo a colocar o dedo para sentir se meus olhos estavam enganados ou não" (MOSHENSKA, 2011: 27). Pepys se sentia livre e confortável em tocar a pintura, mas não relata a reação de Everelst ao toque da pintura, o que talvez indique que não era nenhum absurdo o que ele estava fazendo, principalmente se considerarmos otrompe l'oeil, um estilo artístico que, ao enganar o observador, praticamente o convida ao toque (SLUIJTER, 2000).

Embora hoje possa nos parecer um grande absurdo, há evidências de a prática do toque ter sido um procedimento corrente e usual. Por exemplo, em 1694, a viajante e exploradora Cecilia Finnes, ao relatar sua visita ao Asmolean Museum, nos fala de um bastão que lhe chamou a atenção: "por mais que parecesse pesado e sólido ao olhar, ao tocá-lo percebo que é leve como uma pluma" (1949: 33). Como ressalta Foster (2013), ao segurar o objeto, Finnes sublinha um aspecto essencial da prática dos museus antigos, a interação com as peças expostas. $\mathrm{O}$ acesso tátil aos objetos fornecia um meio 
direto para a aquisição de conhecimento que sobrepunha o risco potencial de danificar ou mesmo de roubar tais objetos. Como salienta Classen (2007),o exame tátil dos objetos permitia um conhecimento encorpado da natureza da Cultura Material. Ao tocar, ao interagir com os objetos, o visitante se unia a eles, criava uma relação de intimidade, de proximidade que permitia não apenas a criação de memórias, mas a possibilidade do devaneio criativo (BACHELARD, 1998).

O toque também fornecia a possibilidade de atestar a verdade do mundo. Benedetto Varchi, em 1549, em seu DueLezione, defendiaque, devido ao fato de podermos tocar nas esculturas, elas se tornavam uma espécie de arte mais verdadeira do que a pintura, já que pelo toque, podemos verificar a existência externa dos objetos. Barkan (1999) nos mostra que o escultor florentino Lorenzo Ghiberti, ao retirar uma estátua dos esgotos de Roma no século XVI, inspeciona os danos na escultura não com os olhos, mas com as mãos, pois o toque poderia revelar sutilezas que os olhos não poderiam alcançar. O poeta inglês Sir John Davies expressa claramente, em seu poema Nosce Teipsum, de 1599, a ideia do tato como fonte do aprendizado do mundo.

Pelo toque, as primeiras qualidades puras nós aprendemos. Que vivificam todas as coisas, quentes, frias, úmidas e secas. Pelo toque, o duro, o macio, o áspero e o liso nós discernimos. Pelo toque o doce prazer e a dor aguda nós tentamos. (DAVIES, Nosce Teipsum apud WOLF, 2004:19).

Sei que há toda uma questão associada à preservação e à conservação na ideia do toque de objetos institucionalizados. Esse é um debate cada vez mais acalorado dentro das humanidades (DAY, 2013). Mas creio que essa é só a ponta do iceberg. Acho que há algo mais profundo, mais velado no não tocar que é a caracterização do ser enquanto um ser educado, civilizado. Tocar e não tocar estabelece um jogo de poder, de autoridade, que qualifica o Eu e o Outro. Nós, no ocidente, aprendemos que não é educado tocar, seja um objeto em um museu ou uma pessoa na rua. Quantas vezes você ouviu sua mãe lhe dizer: "Não toque nisso, é falta de educação!"? Aprendemos desde crianças que o toque é o mais baixo dos sentidos. Quando crescemos e viramos cientistas, aprendemos que a ciência não se faz com o toque, pois o toque vem acompanhado do $\mathrm{Eu}$, vem acompanhado da subjetividade, e a ciência deve ser distanciada, neutra e objetiva. Essa ideia, entretanto, não é nova no Ocidente. A noção do tato como um sentido menor é uma construção que encontra suas raízes no pensamento aristotélico e, sendo assim, para entendermos como o tato foi excluído da 
experiência dos museus, da experiência da arte, da Arqueologia, enfim, do nosso dia a dia, precisamos primeiramente voltar à Grécia Antiga e a Aristóteles.

\section{Tocando a História}

Segundo Aristóteles, a alma era composta de três faculdades: a Faculdade Nutritiva, a Faculdade Perceptiva e a Faculdade Cognitiva. A Faculdade Nutritiva é a primeira e mais básica de todas as faculdades da alma, sendo associada às capacidades dos seres vivos de se alimentar. Tanto homens quanto plantas e animais apresentam a Faculdade Nutritiva, já que, para sobreviverem, todos precisam se alimentar. Ligada à Faculdade Nutritiva está a Faculdade Perceptiva, que teria como função informar à alma as coisas do mundo. A Faculdade Perceptiva é o que separa as plantas dos animais, já que as plantas apresentam apenas a Faculdade Nutritiva. Assim, podemos falar que a faculdade Perceptiva é a primeira e mais básica característica dos animais. Além disso, aqueles seres que apresentam a Faculdade Perceptiva apresentam também a Faculdade Desiderativa, ou seja, o desejo, pois a percepção induz o apetite e a vontade.

Na Faculdade Perceptiva, o tato representa o aspecto mais essencial. Para Everson (2007), isso se dá porque a racionalidade aristotélica dá à Faculdade Perceptiva uma função prática, ou seja, de perceber o alimento em seu entorno. Os animais precisam identificar seu alimento no mundo e como nem todos os animais podem se mover em direção ao alimento percebido, o tato se configura como a primeira e mais básica das sensações. Ele está presente em todos os animais como aspecto primário da sensação (ARISTÓTELES, De Anima, 414b15). Nesse sentido, enquanto a faculdade da nutrição é a faculdade da alma que primeiramente caracteriza um ser vivo, o tato é o sentido que inicialmente caracteriza os animais, ou seja, o que diferencia os animais dos demais seres vivos é justamente o tato. Aqui, está um ponto importante e que será fundamental na significação do tato nos períodos subsequentes da história. Sendo assim, guardemos esta informação:

a) O tato como elemento definidor da vida animal

Segundo o filósofo, as sensações não são produzidas pelo órgão sensorial, mas sim pela ação de um intermediário. Dessa maneira, ao percepcionarmos, o objeto da percepção move o intermediário que, por sua vez, age diretamente no órgão sensorial, 
causando a sensação. O intermediário da visão é o transparente, o da audição é o ar, o do olfato é uma substância indefinida. São Thomas de Aquino, ao comentar o $D e$ Anima, atribui ao vapor a ação de intermediário do olfato. Já no caso do paladar e do tato, o intermediário é o corpo. A diferença entre o paladar e o tato e os demais sentidos é que, enquanto a visão, a audição e o olfato ocorrem à distância, no caso do tato e do paladar a sensação ocorre simultaneamente à ação do intermediário. Sendo assim, podemos dizer que é através do corpo que todas as sensações do tangível são geradas. Esse é um segundo aspecto importante na caracterização posterior do tato, ou seja, a identificação do tato com o corpo. Guardemos também esta informação:

b) O tato associado às coisas da carne, do corpo, ao carnal

Com os primeiros pensadores cristãos, os sentidos deixam a arena puramente prática para assumirem uma posição moral. O problema é que, ao assumir tal conotação, os sentidos entraram em conflito com a razão. De acordo com Santo Agostinho, o pecado original nada mais é do que a permanente rebelião do desejo contra a razão. Segundo Kupper (2008), a ideia do pecado original representa a categórica exclusão da possibilidade de a humanidade agir moralmente através de sua própria racionalidade. Sendo assim, a ideia do pecado original significa a fraqueza da razão e do julgamento racional.

A questão é que tanto os desejos quanto a razão, na filosofia cristã medieval, nascem dos sentidos. Segundo Spiegel (2008), como os sentidos não podiam ser deixados de lado, já que eles eram considerados o meio através do qual os seres encorpados adquirem informação do mundo, sendo necessários para a autopreservação, aquilo que preservava a vida resultava inexoravelmente na destruição metafísica do ser. Controlar os sentidos a fim de evitar as tentações representava limitar as possibilidades de conhecimento do mundo. Dessa maneira, para os cristãos na Idade Média, os sentidos funcionavam como a base para a manutenção da vida, ao mesmo tempo em que funcionavam como a principal causa da morte espiritual (SPIEGEL, 2008). Essa fundamental incoerência na doutrina dos sentidos é bem atestada no texto medieval Arcipreste de Talavera, de Afonso Martinez Toledo, publicado em 1438, onde se contrapõem a descrição e a dura denúncia dos prazeres dos sentidos. Para Santo Agostinho, os órgãos sensoriais não eram maus por natureza, mas se tornavam maus e propensos ao pecado quando o sentido interno (sensus interioris) falhava em controlá- 
los. Se na doutrina aristotélica a razão comanda os desejos, na doutrina cristã dos sentidos é o desejo que comanda a razão. Essa relação entre a razão e o desejo, que Spiegel (2008) chama de histérica, vai conduzir ao repúdio generalizado dos sentidos na cristandade ocidental. Os exercícios espirituais de Santo Inácio de Loiola, assim como o desenvolvimento das práticas ascéticas, são o exemplo mais claro desta política de contenção e controle das impressões sensoriais.

De modo geral, a desconfiança cristã com os sentidos fez com eles fossem concebidos como portas que permitiam a tentação, o vício e o espírito maligno. Para Santo Agostinho, dentre todos os sentidos, o mais perigoso era o tato, visto que ele afetava o corpo como um todo. O toque do corpo de uma mulher contra o corpo do homem era tido como a forma de sensibilidade mais avassaladora e perigosa à sensibilidade masculina:

A palavra luxúria (libido) usualmente sugere à mente a excitação do órgão de geração. E esta luxuria não somente toma o corpo todo e os membros externos, mas faz ele mesmo sentir dentro e assim move-se o conjunto da alma humana com uma paixão (voluptas) na qual a emoção mental é misturada com o apetite carnal, sendo o prazer resultante, o maior prazer de todos os prazeres corporais. (SANTO AGOSTINHO, A Cidade de Deus, XVI).

Mesmo Aristóteles já havia ressaltado a ligação dos prazeres carnais com o tato. Aqui, temos o terceiro aspecto importante da significação do tato no mundo ocidental, ou seja, sua associação com as tentações carnais. Já sabemos que o tato era concebido como o sentido que nos define como animais. Sabemos também que o tato está ligado ao corpo. Agora sabemos que, por sua ligação com o corpo, o tato era tido como o sentido da luxúria, do vício e das tentações, ou seja:

c) O tato como porta para o pecado e para a luxúria

Com o advento do projeto modernista no ocidente, os sentidos foram perdendo sua conotação moral para se tornarem cada vez mais marcadores sociais. Em $O$ Processo Civilizatório, Norbert Elias (1994) defende que o principal aspecto da modernidade é a disciplina do Eu. Essa busca pela disciplina do corpo ajudou a interiorizar o tato e relegá-lo ao domínio afetivo no início da Modernidade. Enquanto na Idade Média alimentar-se com as mãos reafirmava relações comunais, criando uma ideia de igualdade social ao não permitir individualismo,no oitocentos desenvolvia-se a 
ideia de manter a mão consigo mesmo (CLASSEN, 2012). O homem da corte passa a ser controlado, disciplinado, com toque preciso e coreografado, tal como a noção europeia de civilização, de cultura, requeria. Assim, a supressão não só do tato, mas de todos os outros chamados sentidos inferiores: paladar e olfato. Galileu nos oferece uma evidência marcante acerca dos debates em curso nas elites europeias no que diz respeito à relevância do tato para a experiência da beleza. Em uma carta datada de 26 de junho de 1612, dirigida a seu amigo, o pintor Lodovico Cigoli, Galileu vai direto ao ponto: "podemos ser capazes de tocar estátuas, mas isto não é certamente o modo de apreensão para os quais elas se destinam" (MOSHENSKA, 2011: 26). Galileu reforçava assim a ideia aristotélica que excluía o tato da experiência do belo.

As hierarquias raciais surgidas no século XVIII demostram claramente essa ideia. O naturalista Lorenz Oken, por exemplo, defendia uma hierarquia racial dos sentidos, onde os africanos apareciam associados ao tato, os australianos e melanésios ao paladar, os nativos americanos ao olfato, os asiáticos à audição e os brancos europeus apareciam associados à visão (HOWES, 2009). Dias (2004) demostrou, a partir da análise dos Proceedings da Societé d'Anthropologie de Paris, entre os anos de 1859 e 1890, como, através da medição das capacidades sensoriais dos indivíduos, buscou-se na realidade dar cientificidade aos pressupostos que viam nos povos primitivos maior acuidade tátil, olfativa e gustativa, e no homem branco europeu maior acuidade auditiva e, sobretudo, visual. Como o tato era associado diretamente com o corpo e não com a mente, o corpo avantajado de muitos indígenas confirmava o estereótipo da acuidade tátil dos "selvagens". Partia-se, assim, de uma hierarquização sensorial para uma hierarquização social, com os brancos europeus no topo da escala e os negros e indígenas na parte inferior. Este é o quarto aspecto a destacar na construção do tato no Ocidente:

d) O tato associado ao "selvagem, ao inculto, ao não civilizado"

Nas ciências, Kant e Descartes passam a defender que o tato não permitia o pensamento reflexivo. Para os filósofos, ao utilizarmos a visão, não somos obrigados a estabelecer um contato físico com o percepto. Nós não interferimos no objeto e o objeto não sofre alteração ao ser percebido e, como não há relação causal na visão, o ganho é a objetividade (JONAS, 1966). Já quando utilizamos o tato, há uma necessidade tácita de contato, o que causa mudança tanto no percepto quanto no observador. Ao tocar um 
objeto, nós alteramos o objeto e o objeto nos altera: basta pensar que, no mínimo, há uma alteração na temperatura tanto na superfície do objeto quanto na ponta dos dedos. No tato, nós não temos uma clara separação entre a função teórica da informação e seu condutor prático. Dessa maneira, a visão passa a representar o sentido da razão, enquanto o tato passa a representar o sentido da subjetividade. Este é justamente o último aspecto que caracteriza o tato no ocidente:

e) O tato como veículo da subjetividade

A partir dessas cinco construções, ou seja, do tato como sentido animal, como representante do corpo, como porta para o pecado, como símbolo do selvagem e como fonte da subjetividade, podemos entender como o tato foi sendo paulatinamente construído e adquiriu significado de um reflexo de nosso lado animal, irracional e brutal. Nesse contexto, o tato passou a representar, na modernidade, um símbolo de tudo que era tido como lamentável na alma e na conduta humana. O ápice dessa construção veio em 1844, com a escritora e crítica de arte Anna Jameson. Ao comentar sobre o público que frequentava os museus europeus, a autora escreveu:

\footnotetext{
Nós podemos lembrar os indolentes e vadios que ao invés de se moverem entre as belezas e maravilhas com reverência e graça, escoravam-se sobre elas como se tivessem o direito de estarem lá, falando, flertando, tocando os objetos e mesmo as pinturas! (HERMANN, 1972: 126).
}

A escritora articulava com sua fala um conceito específico de classe e utilizava a estética sensorial para construir a ideia do outro, do inculto. Segundo a autora, somente plebeus e incultos tocam obras de arte. O novo regime sensorial defendido por ela, com a visão sendo considerada o sentido superior, e o tato o inferior, afastava as pessoas da vivência do mundo e dos objetos, passando, assim, a representar um regime de exclusão social. Dessa maneira, uma forma distinta de ver e perceber o mundo ganhava sua ascendência pública definitiva. Tinha início, assim,o Império da Visão. Tocar os objetos passava a ser considerado um exemplo de ignorância, de falta de educação. Os objetos, nesse cenário, deixam a arena da experimentação e passam à arena da observação. 


\section{Olhe, mas não toque!!!}

A construção do tato como símbolo do ignorante, do selvagem, foi acompanhada por uma série de mudanças sociais, políticas e ideológicas que resultaram na mudança das práticas de exibição. Enquanto os sentidos menores eram reprovados, visão e audição ganhavam cada vez mais proeminência nas práticas sociais no Ocidente, e as instituições culturais como os museus, bibliotecas e parques se tornavam veículos para o exercício dessas novas formas de poder (BENNETT, 1995; THOMAS, 2009). As galerias se transformam em locais tanto para a observação quanto para a regulação social. Dentro desse espaço politizado, ordenado, o corpo do visitante poderia ser moldado de acordo com os novos códigos de conduta social a partir da implementação de regras de comportamento elaboradas por meio de restrições relacionadas à vestimenta, alimentação e proibição do toque. (DAY, 2013). Não tocar, não comer, não falar em voz alta, vestir-se adequadamente definiam o Eu e o Outro.

A mudança das políticas de engajamento corporal com a Cultura Material para as políticas de distanciamento colocou os museus arqueológicos e etnográficos em uma posição desvantajosa em relação à apresentação de uma narrativa sensorial e encorpada do passado. Muitos museus modernos têm tentado quebrar essa barreira (MORGAN, 2011), buscando novas estratégias para permitir um maior envolvimento do público. Mas a prática geral continua perpetuando a visão como principal meio de apreensão do passado, colocando o visitante em uma posição de espectador passivo, com pouca ou nenhuma participação (CLASSEN \& HOWES, 2006).

Apesar de os cientistas sociais hoje estarem, em sua maioria, conscientes da construção problemática da visão como sentido da razão, esse sentido permanece nosso instrumento epistemológico e ontológico mais penetrante (OUZMAN, 2005). Segundo Thomas (2009), a emergência durante o século 18 da visão como sentido principal no ocidente não representa apenas a emergência de uma preferência cultural por um sentido específico, mas uma situação na qual uma concepção particular e restrita de visão se torna o modo aprovado de apreender a realidade e produzir regimes de verdades. Muito da Arqueologia e das práticas de institucionalização da Cultura Material levam a forma de um testemunho de apropriação, onde testemunho implica mais do que olhar, significando o estabelecimento de uma relação psicológica na qual o observador é superior ao objeto da observação. É nesse ponto que começa nossa autoridade como cientistas. 
Mas, a despeito da conveniência analítica, o foco num único sentido ignora dois fatos: em primeiro lugar, que o modelo sensorial, com seus cinco sentidos autônomos, pode não ser o modelo mais apropriado para o entendimento das experiências sensoriais do passado, já que grupos não ocidentais podem valorizar outras modalidades sensoriais, como têm demonstrado as evidências históricas, etnográficas e antropológicas; e, em segundo lugar, que a experiência sensorial é multifacetada e age em conjunto.

Pensemos, por exemplo, na cestaria dos povos da etnia Desana, que vivem nas margens do rio Uapésna Amazônia. Segundo Reichel-Dolmatoff(1985) e Classen e Howes (2009), entre os Desana, as cestas, assim como os tapetes de fibra, além do caráter prático utilitário, possuem um valor simbólico que está diretamente associado ao odor e à textura das matérias primas utilizadas para sua confecção, pois os odores e texturas das diferentes fibras utilizadas na criação desses objetos fazem referência direta à mitologia Desana. Ao institucionalizarmos esses objetos em redomas de vidro, não permitindo o acesso do público às relações sensoriais que permeiam a Cultura Material, estamos limitando o entendimento de tais objetos, pois eles precisam ser vivenciados pelo toque e pelo odor para serem entendidos.

Outro objeto que se destaca por extensão sensorial é o anel Kula dos Massins de Papua, Nova Guiné. Segundo Howes (2005), odor, sinestesia e audição são aspectos destacados dentro dos modelos sensoriais do grupo dos Massins. Ser buto, ou seja, ser barulhento é um símbolo de status e destaque social entre os Massins. O anel Kula, nesse cenário, é uma materialização dos modelos sensoriais, visto que seus adereços lhe conferem sonoridade, movimento e odor. Se Howes tem razão ao interpretar os anéis Kula como objetos que ganham sua importância pelo som e pela textura, como o arqueólogo, por exemplo, pode compreendê-lo tendo a visão como principal ferramenta analítica? E como o público, que não pode sequer manusear um anel Kula, pode chegar a compreendê-lo em sua plenitude?

Não podemos pensar que objetos são apenas textos para serem lidos ou sinais visuais que precisam de codificação: acima de tudo, objetos são formas materiais que pressupõem uma inter-relação corporal sinestésica. Ao não considerar os aspectos associados à experimentação corpórea, sensorial dos objetos, estamos, em grande parte, limitando nosso próprio entendimento da Cultura Material, e, ao mesmo tempo, estamos impedindo que outras vozes possam contribuir diretamente para a formação do conhecimento, tanto do presente quanto do passado. Ao nos tornarmos detentores do 
conhecimento e das verdades do mundo, estamos excluindo sistematicamente aqueles que não compartilham dos mesmos modelos defendidos pela ciência. O que realmente nos dá o direito de determinar o que é ou não um determinado objeto? O que nos dá o direito de dizer que isto ou aquilo pode ser ou não tocado? A ciência? A autoridade científica nos dá o direito de tocar nos objetos, de quebrar fragmentos que não nos interessam, de escavar e modificar uma paisagem, mas ao mesmo tempo essa autoridade científica não permite que populações que vivem às margens daquilo que a ciência chama de patrimônio arqueológico possam tocar, remover, modificar objetos e paisagens, ou que visitantes em museus possam sentir os objetos, ou mesmo que decidam se algo é ou não importante. A ciência nos dá a autoridade de institucionalizar a Cultura Material, de imobilizar um dado objeto em uma redoma de vidro de acordo com os modelos sensoriais ocidentais e científicos, mas tira das pessoas a oportunidade de sentir e tocar os objetos.

Ao ressignificarmos os objetos, nomeando-os como artefatos arqueológicos, estamos criando novas histórias sobre esses objetos. Mas essas histórias são narrativas políticas sem vida, sem alma, pois estamos submetendo esses mesmos objetos a discursos desencorpados. A quem atende a sacralização que fazemos do objeto narrado enquanto artefato arqueológico? Ao governo? À sociedade? A essa última com certeza não, pois, frequentemente, excluímos o público em geral de todos os processos de conhecimento, sobretudo aquele que porta alguma deficiência física. O que deve fazer, por exemplo, um deficiente visual em uma exposição museológica? Será que não deveríamos abrir nossas redomas de vidro a fim de permitir o contato físico das pessoas com a materialidade? Afinal de contas, não foi para isso que os objetos foram criados, para serem experimentados? Sei que alguém pode me falar: mas Zé, nem todos os objetos foram criados para serem tocados, experimentados, pois há algumas categorias de objetos que são e foram criadas justamente para serem contemplados a distância. Sei perfeitamente que nem todos os objetos pressupõem o toque ou mesmo um contato corporal mais intenso, mas é por isso que temos que ter muito cuidado e responsabilidade ética ao tirar um objeto de seu contexto e inseri-lo em outro contexto, pois nesse processo de ressignificação, os objetos perdem sua identidade e passam a assumir uma nova personalidade, a de patrimônio. Creio que temos que dar uma oportunidade aos objetos e às pessoas, para que eles possam se entender e se descobrir, sem que tenhamos nós, os auto proclamados "guardiães do patrimônio", que interferir tão marcadamente nessa relação. Com a quantidade tão infinda de materiais abarrotando 
nossas reservas técnicas, não seria a hora de disponibilizar parte desse material para o toque, assim como para os outros sentidos que não os da visão? Sabem por que não fazemos isso? Porque fomos ensinados a somente acreditar na visão e não nos demais sentidos, principalmente naqueles que chamamos de sentidos inferiores e que, em geral, nem lembramos que temos. Essa educação é tão forte que acreditamos realmente que a visão é o sentido superior, o sentido da razão e o tato o sentido inferior, o sentido do inculto, o sentido do selvagem.

Bloch (1991) e Benjamin (1969) tratam a estrutura perceptiva do dia a dia na modernidade como a experiência de um contínuo mítico. Esse contínuo, que na verdade é ideológico, é experimentado de modo particular, subjetivo e culturalmente estabelecido. Dentro desse contínuo, modelos perceptivos são disseminados a fim de manter uma memória pública dominante e eliminar as chamadas memórias discordantes. A força de tal educação se assenta no fato de que, quando experimentamos algo como natural, nós o experimentamos como verdadeiro e é justamente por isso que a estrutura do contínuo é perniciosa. A inconsciência da experiência do contínuo no dia a dia, que Braudel (1980) apresentava como algo quase orgânico, Benjamin (1969) e Bloch (1991) descrevem como uma construção político-social. Esse contínuo, no qual os discursos e as materialidades são politica e culturalmente determinadas, permeia a experiência sensorial mundana do cotidiano e acaba por gerar os processos de lembrança e esquecimento. Museus, nesse sentido, em sua maioria, estão perpetuando uma forma específica de memória que é construída somente e tão somente pela visão, perpetuando uma visão de mundo que pertence ao homem civilizado ocidental.

O conhecimento discursivo, visual, é um fetiche de nossa tradição acadêmica, que é incapaz de descrever a maneira pela qual um artesão entendia e trabalhava com seus materiais. É necessário explorar os mecanismos através dos quais a estrutura perceptiva é formada, se quisermos minimamente entender como as pessoas no passado experimentavam a materialidade. Se quisermos realmente entender como as pessoas se engajavam no dia a dia com seu mundo, precisamos reconstruir a história do sensorial dessas pessoas. Temos que colocar de lado a ideia moderna de que os sentidos são apenas receptores de informação e admitir que os sentidos são socialmente construídos.

Uma abordagem sensorial da Cultura Material, nesse sentido, tem o potencial para articular subjetividades emergentes que encorpam realidades, imaginação, razão, diferenças e sentido comum. Uma abordagem sensorial da Cultura Material a posiciona como integral ao comportamento humano e não como um aspecto isolado e inerte. 
Como defende Ouzman (2005), uma maior apreciação da Materialidade ou da Cultura Material partindo de seus aspectos sensoriais permite uma reflexão da maneira pela qual aceitamos ou refutamos uma dada informação, pois os sentidos podem desafiar as verdades da visão. É nesse sentido que uma Arqueologia Sensorial pode nos ajudar, ao oferecer abordagens diferenciadas da Cultura Material, pois a construção do próprio patrimônio arqueológico pode, então,basear-se em modelos sensoriais que não o científico e ocidental. A partir daí, assume-se a possibilidade de diversas apropriações sensoriais do patrimônio não apenas pelos cientistas, como também pelo público em geral, chegando mais perto de uma "gestão compartilhada" (BEZERRA, 2011) desse patrimônio, na qual o público tem uma participação ativa. Precisamos quebrar as redomas de vidro e permitir que todos tenham acesso à formação de conhecimento, seja pelo tato, seja pela visão.

\section{Referências bibliográficas}

AgOSTINHO. A Cidade de Deus. $7^{\mathrm{a}}$ ed. Trad. Oscar Paes Lemes. Rio de Janeiro, Editora Vozes, 2002.

ARISTÓteleS. Da Alma (De Anima). Trad. Ana Maria Lóio. Lisboa, Imprensa Nacional Casa da Moeda. 2010

BACHELARD, G. A Poética do Espaço. São Paulo: Editora Martins Fontes. 1998.

BARKAN, L. "Unearthing the Past: Archaeology and Aesthetics" In: the Making of Renaissance Culture. New Haven, Yale University Press, 1999.

BENJAMIN, W. "The Work of Art in the Age of Mechanical Reprodution". In: Illuminations. Hannah Arendt (ed.). New York, Schocken, pp. 83-109. 1969

BENNET, T. The Birth of the Museum: History, Theory, Politics. London: Routledge. 1995.

BEZERRA, M. "As moedas dos índios: um estudo de caso sobre os significados do patrimônio arqueológico para os moradores da Vila de Joanes, ilha de Marajó, Brasil". Boletim do Museu Paraense Emílio Goeldi.CiênciasHumanas, vol. 6: 57-70. 2011.

BLOCH, E. Heritage of Our Time. Berkley, University of California Press. 1991

BRAUDEL, F. On History. Trad. Sarah Matthews. Chicago: University of Chicago Press. 1980.

CHATTERJEE, H. Touch in Museums: Policy and Practice in Object Handling, Oxford, Berg. 2008. 
CLASSEN, C. "Museum Manners: The Sentidory Life of the Early Museum". In: Journal of Social History, 40: 895-914. 2007

Illinois Press. 2012

The Deepest Sense.A Cultural History of Touch. Chicago, University of

CLASSEN, C; HOWES, D. "The Museum as Sensescape": Western Sensibilities and Indigenous Artifacts. In: Edwards, E, C Gosden and R.B Philip, Sensible Objects. Colonialism, Museums and Material Culture. Oxford and New York, Berg, 199-222. 2006.

DAY, J. Making Sense of the Past. Towards a Sentidory Archaeology. Center for Archaeological Investigation Occasional Paper, n. 40. Southern Illinois University. Carbondale. 2013.

DIAS, N. La Mesure des Sens: les Anthropologues et le Corps Humainaux XIX é siècle. Paris: ÉditionsFlammarion.2004

ELIAS, N. O processo civilizador: Uma história dos costumes. Rio de Janeiro: Jorge Zahar, 1994, v I.

EVERSON, S. Aristotle on Perception. New York, Oxford University Press. 2007

FIENNES, C. The Journeys of Cecilia Fiennes. Cresset, London, 1949.

FOSTER, C. "Beyond the Display Case: Creating a Multisentidory Museum Experience". In: Day, J. 2013. Making Sense of the Past. Towards a Sentidory Archaeology. Center for Archaeological Investigation Occasional Paper, n. 40. Southern Illinois University.Carbondale. Pp. 371-389. 2013.

GELL, A.Art and Agency: An Anthropological Theory. Oxford: Clarendon Press. 1998

HERMAN, F. The English as Collectors.London, Chatto\&Windus. 1972.

HOWES, D. Empire of Senses: The Sensual Culture Reader. Berg, Oxford. 2005

"Introduction: The Revolving Sentidorium". In: HOWES, D. (Ed.). The Sixth Sense Reader. Oxford: Berg, pp. 1-542009

HOWES, D; CLASSEN, C. Doing sentidory anthropology. 2009. In:

www.sentidorystudies.org/?page_id=355 acessado 07/01/2014

JONAS, H. "The Nobility of Sight: A Study in the Phenomenology of the Senses". In: Jonas, H. The Phenomenon of Life: Toward a Philosophical Biology. New York: Harper \& Row, pp.135-156. 1966.

JONES, A. "Drawn from memory: the archaeology of aesthetics and the aesthetics of archaeology in Earlier Bronze Age Britain and the present". World Archaeology 33 (2), 334-356. 2001. 
KUPPER, J. "Perception, Cognition, Volition in the Arcipreste de Talavera". In: NICHOLS, S.; KABLITZ, A.; CALHOUN, A. (Eds.). Rethinking the Medieval Senses, Heritage, Fascinations, Frames. Baltimore: John Hopikins University Press, pp. 119153. 2008.

MORGAN, J. Change and everyday practice at the museum: an ethnographic study. $\mathrm{PhD}$ thesis, University Manchester, 2011.

MOSHENSKA, J. Feeling Pleasures: The Senses of Touch in Renaissance England . A Dissertation Presented to the Faculty of Princeton University in Candidacy for the Degree of Doctor of Philosophy. Department of English. New Jersey, 2011.

PYE, E. "Introduction: the power of touch". In: E. Pye (ed.) The Power of Touch: Handling Objects in Museum and Heritage Contexts, Walnut Creek: Left Coast Press, 13-30. 2007

SLUIJTER, E. Seductress of Sight: Studies in Dutch Art of the Golden Age. Trad.Jennifer Kilian and Katy Kist. Zwolle, Waanders, 2000.

SPIEGEL, G. "Paradoxes of the Senses". In: NICHOLS, S.; KABLITZ, A.; CALHOUN, A. (Eds.). Rethinking the Medieval Senses, Heritage, Fascinations, Frames. Baltimore: John Hopikins University Press, pp. 186-193. 2008.

THOMAS, J. "On the ocularcentrism of archaeology". In Archaeology and the Politics of Vision in a Post-Modern Context, ed. Julian Thomas, Vitor Jorge, pp. 1-12. Cambridge, Cambridge Scholar's Press. 2009

OUZMAN, S. "Prose has its Cons. Seeing Beyond Material Culture as Text". Paper presented to the Congress Seeing the Past: Building Knowledge of the Past and Present through Acts of Seeing. Stanford Archaeology Centre, Stanford University, USA, $5^{\text {th }}-$ $6^{\text {th }}$ February, 2005

REICHEL-DOLMATOFF, G. Basketry as Metaphor: Arts and Crafts of the Desana Indians of the Northwest Amazon. Los Angeles: Museum of Cultural History, University of California. 1985.

WOLF, C. "Epicuro Cartesianism: La Mettrie'sMaterialistTransformation of Early Modern Philosophy". In: HECHT, H. (Ed.). La Mettrie. Ansichten und Einsichten. Berlin: Berlin Wissenschafts-Verlag, pp. 75-95. 2004. 